\title{
Audit in practice
}

\section{Patients transferred from a regional adolescent unit to adult wards within the same hospital}

\author{
D. J. Rothery, Consultant Adolescent Psychiatrist; R. PARmar, Senior Registrar; \\ and M. Broughton, Registrar, Irwin Unit For Young People, Hollymoor Hospital, \\ Tessall Lane, Northfield, Birmingham B31 5EX
}

In 1986 the report Bridges over Troubled Waters (NHS Health Advisory Service, 1986) stated quite categorically that patients under the age of 16 should not be treated in adult psychiatric wards. The National Association for Children in Hospital has also worked tirelessly against children and adolescents being treated in adult hospital wards, although this has mainly concerned the paediatric, medical and surgical fields. However few guidelines were laid down about the function of psychiatric units for children and adolescents when the majority of such units were first being established in the late 1960 s and early 1970s. Indeed in the circular from the Ministry of Health (1964) about the need for such units it was stated that some adolescent patients could suitably be treated in adult wards. However no age limits were specified in the circular. There have been no specific guidelines issued subsequently by the Department of Health about the use of adult psychiatric beds for adolescents.

Clearly for all children and the vast majority of young adolescents it is desirable that any in-patient psychiatric treatment they require is carried out in the context of specialist child and adolescent units. However it is possible that some adolescents may benefit from being on an adult ward. Additionally it seems likely that some extremely disturbed and ill adolescents will have to be nursed on adult secure wards because of the lack of suitable secure psychiatric adolescent units nationally.

This study is an attempt to define the characteristics of the patients, the reasons for transfer to an adult ward and the effect of that experience on the young person.

\section{The study}

The regional adolescent unit at Hollymoor first opened in 1969 and from its inception the consultant in charge had an arrangement with her colleagues in adult psychiatry that adolescents could be admitted to adult wards including the locked ward if necessary. All such transfers were recorded. This arrangement has made it possible to carry out a retrospective case-note study of those patients who have been transferred to adult wards, over the 21 years of the unit's existence. All the case-notes of the young people transferred to adult wards who were patients of the adolescent unit consultants were studied. Information on age, sex, psychiatric diagnosis (using ICD-9), length of stay both on the adolescent unit and the adult ward, reasons for transfer stated in the notes, effect on behaviour and mental state of the patient, type of adult ward, and use of the mental health act child care legislation was collected.

\section{Findings}

One hundred and sixty-three patients resulting in $\mathbf{1 7 0}$ admissions (seven patients had two admissions) involving transfer to an adult ward within the same hospital were identified. Five sets of notes could not be traced. Taking out those transfers to adult wards which were a result of the unit either being full or closed left 119 admissions. Of these, $73(61 \%)$ were males. The mean age of the patients was 15 years with a range of 12 to 18 years. Seventy-nine (72\%) patients were transferred to an open adult ward and $40(28 \%)$ patients were transferred to an adult secure ward. The number of transfers has significantly reduced over the past eight years. From 1969 to 1983, although there was some year to year variation, there were six transfers a year, on average. From 1984 to 1988 there were three transfers a year with only four transfers over the last three years to 1991 .

In terms of the legal status of the patients, the findings were that $65 \%$ of the secure group were transferred on the basis of parental consent, $20 \%$ on the basis of the consent of social services, and only $15 \%$ on the basis of a section of the Mental Health Act. 
TABLE I

Diagnosis (ICD-9)

\begin{tabular}{ll}
\hline 1. Mixed conduct and emotional disorder & No $=25(21 \%)$ \\
2. Conduct disorder & No $=28(23 \%)$ \\
3. Schizophrenia & No $=20(17 \%)$ \\
4. Depressive disorder & No $=9(7 \%)$ \\
5. Uncertain & No $=8(7 \%)$ \\
6. Hypomania & No $=6(5 \%)$ \\
7. Parasuicide & No $=6(5 \%)$ \\
8. Other & No $=17(15 \%)$ \\
\hline
\end{tabular}

TABLE II

Comparison of patients transferred to open and closed wards

\begin{tabular}{lcc}
\hline & $\begin{array}{c}\text { Open Ward } \\
n=79\end{array}$ & $\begin{array}{c}\text { Closed Ward } \\
n=40\end{array}$ \\
\hline Mean age & 15.1 yrs & $14.9 \mathrm{yrs}$ \\
Females & $38(48 \%)$ & $8(20 \%)$ \\
Males & $41(52 \%)$ & $32(80 \%)$ \\
Mean stay & 11.2 weeks & 8.4 weeks \\
& & \\
Diagnosis & & \\
Conduct/mixed & $35(44 \%)$ & $18(45 \%)$ \\
Schizophrenia & $10(13 \%)$ & $10(25 \%)$ \\
Mania & $1(1 \%)$ & $5(12 \%)$ \\
Depression & $8(10 \%)$ & $1(2 \%)$ \\
Parasuicide & $6(8 \%)$ & $0(0 \%)$ \\
& & \\
Reason for & & \\
transfer & & \\
No behavioural & & \\
control & $24(30 \%)$ & $0(0 \%)$ \\
Aggression & $5(6 \%)$ & $14(35 \%)$ \\
Absconding & $2(3 \%)$ & $17(43 \%)$ \\
Suicidal & $1(1 \%)$ & $8(20 \%)$ \\
Uncertain & $37(49 \%)$ & $1(2 \%)$ \\
Progress & & \\
Improved & & \\
Same & & \\
Worse & $47(59 \%)$ & $22(55 \%)$ \\
Uncertain & $16(20 \%)$ & $13(34 \%)$ \\
\hline & $7(9 \%)$ & $3(6 \%)$ \\
\hline & $9(12 \%)$ & $2(5 \%)$ \\
\hline
\end{tabular}

\section{Comment}

The psychiatrists working on the adolescent unit have always felt that transfer is a valuable clini- cal management option. In the past over half the patients transferred were under 16 years of age. This would not be seen as appropriate by the Health Advisory Service (NHS Health Advisory Service, 1986) and a transfer of an adolescent under that age is now avoided if at all possible.

Aggression is perhaps an understandable reason for transfer to a secure ward, but absconding and being suicidal as reasons for transfer may reflect an unacceptable lack of nursing staff to maintain adequate observation. It is perhaps surprising that so few of the transfers to the secure ward were done on the basis of mental health or childrens' legislation. Present unit policy is only to transfer patients to a secure ward after they have been made the subject of an order under the Mental Health Act.

For some adolescents a move to the secure ward has, on occasions, been a prelude to transfer to social services secure accommodation. Present practice is not to transfer this group of adolescents to the secure ward but to transfer directly to secure accommodation. As regards transfer to the open adult ward, this was often because the adolescents would not abide by what they regarded as petty adolescent unit rules to do with bedtimes and smoking. As the rules on the adult wards were much more liberal on these issues the behaviour of the adolescents often improved.

The findings suggest that transfer to either an open or secure adult ward is not usually a damaging experience for the young person. Only a few patients appeared to deteriorate, indeed many improved. In particular, several patients with an affective psychosis or schizophrenia improved dramatically on moving to an adult ward. A possible reason for this effect is that the ward milieu is more stable and there is less general emotional turmoil on the adult ward due to the older age and greater maturity of the patients.

\section{References}

Health Advisory Service (1986) Bridges Over Troubled Waters. A Report from the NHS Health Advisory Service on Services for Disturbed Adolescents. London: HMSO.

Ministry of Health (1964) In-patient Accommodation for Mentally IIl and Seriously Maladjusted Children and Adolescents. HM (64) 4. London: HMSO. 